\title{
Trabalho e educação: raízes da ontologia da educação da pedagogia histórico-crítica
}

\author{
Work and education: roots of the ontology of the \\ education of historical-critical pedagogy \\ Trabajo y educación: raíces de la ontología de la \\ educación de la pedagogía histórico crítica \\ ADRIANA REGINA DE JESUS SANTOS \\ JOSÉ ALEXANDRE GONÇALVES
}

\begin{abstract}
Resumo: A pretensão deste artigo é compreender as categorias analíticas de Luckacs como elementos para uma ontologia da educação. tendo como foco entender as ideais "lukácsianas" e sua relação com os escritos de Dermeval Savian. A metodologia utilizada tem como base a pesquisa bibliográfica. Ao término deste estudo constatamos que é por meio do entendimento da concepção ontológica do ser, que poderemos restabelecer os vínculos entre conhecimento e trabalho criativo.
\end{abstract}

Palavras-chave: Trabalho. Educação. Ontologia. Pedagogia Histórico-Crítica.

Abstract: The purpose of this article is to understand the analytical categories of Luckacs as elements for an ontology of education. With a focus on understanding the "Lukacsian" ideals and their relation with the writings of Dermeval Savian. The methodology used is based on bibliographic research. At the end of this study, we find that it is through the understanding of the ontological conception of being that we can reestablish the links between knowledge and creative work.

Keywords: Work. Education. Ontology. Historical-Critical Pedagogy.

Resumen: La pretensión de este artículo es comprender las categorías analíticas de Luckacs como elementos para una ontología de la educación. teniendo como foco entender las ideas "lukácsianas" y su relación con los escritos de Dermeval Savian. La metodología utilizada tiene como base la investigación bibliográfica. $\mathrm{Al}$ término de este estudio constatamos que es por medio del entendimiento de la concepción ontológica del ser, que podremos reestablecer los vínculos entre conocimiento y trabajo creativo.

Palabras clave: Trabajo. Educación. Ontología. Pedagogía Histórico Crítica. 


\section{INTRODUÇÃO}

O presente trabalho trata-se de um levantamento teórico que buscou apresentar as contribuições filosóficas de Lukács (2013) ao campo da educação. Assim, relacionamos certos excertos de uma das obras do referido autor com os escritos de Saviani (2007) que propõe uma abordagem dialética para a educação, por meio da Pedagogia Historia-Crítica (PHC). O intuito foi reconhecer que as categorias analíticas estudadas por Lukács (2013), são elementos para uma ontologia da educação, e fundamentos da Pedagogia histórico crítica, vertente bastante discutida no contexto da educação brasileira. Nossa pesquisa teórica apreciou a obra "Para uma ontologia do Ser Social", volume II, de Lukács, com o objetivo de identificar passagens que fizessem menção ao papel da educação para a constituição do ser social. Além do mais, buscamos perceber como as ideais "lukácsianas" dialogam com os escritos de Saviani (2007).

György Lukács, nascido em Budapeste, em 13 de abril de 1885, iniciou na década de 1920 a sua militância política e também sua vida acadêmica, vindo a constituir-se em um influente intelectual marxista. Foi um teórico que se preocupou em argumentar e explicar, dentre outros temas abordados anteriormente por Hegel, Marx, Engels e Lenin, sobre o conceito de Ontologia e o papel que o Trabalho exerce como mediador das relações do Homem - ser social, ou seja, a totalidade genérica manifestando-se no convívio em sociedade.

O referido filósofo do leste europeu é referenciado por Saviani e Duarte (2015) e por outros teóricos educadores brasileiros para fundamentar a problemática da ontologia da educação, ou seja, Lukács (2013), mesmo não se referindo especificamente à educação, abordou uma ampla gama de condicionantes objetivos e subjetivos que interferem na complexidade da vida em sociedade. Uma de suas maiores contribuições à filosofia, a compreensão ontológica do "ser social", é referência essencial na análise teórica da Pedagogia Histórico-Crítica, pois entende a teleologia da construção da humanidade nos indivíduos como produto das relações entre homem e natureza e principalmente entre esse e os demais indivíduos do gênero na coletividade social, nas quais tornam-se imprescindíveis discutir a relação entre trabalho e educação, pois esta, é produto construído a partir das necessidades existentes das relações sociais o que pode possibilitar a criação e/ou reprodução do "ser social". 


\section{TRABALHO: ESSÊNCIA DO SER SOCIAL}

Lukács (2013), em seu livro Para uma Ontologia do Ser Social, obra composta de dois volumes, analisa, no volume II, o Trabalho como categoria central no processo de criação do "ser social". Temática teorizada também em Hegel, Marx, Engels e Lenin, o Trabalho é a categoria central para a ontologia do "Ser Social" de Lukács (2013). Por seu papel de mediador das relações do homem - ser social, a totalidade genérica que se manifesta convívio na coletividade, o trabalho é um conceito primordial, do qual, decorre o entendimento de outras categorias como teleologia, ou seja, a intencionalidade do ato, a reprodução, a alienação, ideologia, entre outras, que irão desencadear os conflitos de ordem ética, entre o interesse particular e o interesse do gênero.

Ontologia, parte da Filosofia que trata do ser enquanto ser, isto é, do ser concebido como tendo uma natureza comum que é inerente a todos e a cada um dos seres. Ontologia é um conceito relevante, pois se vincula ao trabalho e ao processo de consciência que só o ser humano possui em relação ao seu fazer e ser no meio social. Dessa maneira, ontologia seria o conhecimento da essência do ser que, no caso do ser social, está relacionada ao processo de trabalho de constante transformação/produção e reprodução da existência, característica própria do ser humano que procura responder às suas necessidades básicas, ato que gera dominação da natureza, apropriação de saberes, desenvolvimento da racionalidade e formação da cultura. Nesse último aspecto, o desenvolvimento dos costumes e hábitos da vida na coletividade é formado na longa caminhada histórica na qual o homem se torna homem, isto é, um ser social, consciente de si e que se esforça para controlar seus instintos no convívio harmonioso com o outro, mediado pela moral.

Nas palavras de Lukács (2013), além de mudar a natureza, "o trabalho modifica forçosamente também a natureza do homem que o realiza. [...] a questão central da transformação interna do homem consiste em chegar a um domínio consciente sobre si mesmo." (LUKÁCS, 2013, p. 95). De uma maneira bem clara, pode-se entender que, por intermédio do trabalho, o homem transforma-se a si mesmo, se humaniza. Desse modo, o autor segue explicando sobre a centralidade do trabalho no ser social, afirmando que "é por isso que julgamos correto ver no trabalho o modelo de toda práxis social, de qualquer conduta social ativa." (LUKÁCS, 2013, p.62). Lukács é marxista e seus escritos refletem as ideias de Marx, a saber, que a ação conjunta dos homens é mediada por essa categoria essencial que se chama trabalho. Marx (2004) vem a exaltar o mérito de Hegel em sua Fenomenologia do Espírito e o fato de compreender "a essência do trabalho e conceber o homem objetivo, verdadeiro, porque homem efetivo, como o resultado 
de seu próprio trabalho.” (MARX, 2004, p. 123). Entretanto, reiterando uma argumentação exposta acima, um dos erros da dialética hegeliana, aponta Marx (2004), foi o subjetivismo de seu idealismo que se traduz no equívoco de pensar o homem como uma exteriorização da consciência, do pensamento abstrato.

Contudo, revelando a doutrina a qual se identifica, Lukács (2013) apresenta o entendimento importante que o materialismo histórico-dialético atribuiu à categoria trabalho para o salto ontológico entre o homem, ser orgânico/ biológico, para o homem, ser social. Sobre esse aspecto, o autor assim se referiu:

Considerando que nos ocupamos do complexo concreto da sociabilidade como forma de ser, poder-se-ia legitimamente perguntar por que, ao tratar desse complexo, colocamos o acento exatamente no trabalho e lhe atribuímos um lugar tão privilegiado no processo e no salto da gênese do ser social. A resposta, em termos ontológicos, é mais simples do que possa parecer à primeira vista [...]. Somente o trabalho tem, como sua essência ontológica, um claro caráter de transição: ele é, essencialmente, uma inter-relação entre homem (sociedade) e natureza, tanto inorgânica (ferramenta, matéria-prima, objeto do trabalho etc.) como orgânica, inter-relação que pode figurar em pontos determinados da cadeia a que nos referimos, mas antes de tudo assinala a transição, no homem que trabalha, do ser meramente biológico, ao ser social. (LUKÁCS, 2013, p. 35).

O entendimento de que o ser social é síntese do trabalho está no fato de que o homem não tem garantido a sua existência e deve produzir/criar as condições materiais para se manter vivo, e essa realidade faz do trabalho o aspecto mais marcante que diferencia o ser humano de outros animais.

$\mathrm{O}$ autor atribui o mérito por esse entendimento em relação à centralidade do trabalho no processo de humanização do homem aos escritos de Engels. Contudo, essa argumentação de Lukács (2013) vem principalmente das ideias tratadas anteriormente por Marx, nos Manuscritos Econômico-Filosóficos, publicados em 1844, sobre o entendimento de que, como criador de valores de uso, o trabalho é, assim, uma condição de existência do homem, independente de todas as formas sociais, eterna necessidade natural de mediação do metabolismo entre homem e natureza e, portanto, da vida humana (MARX, 2004). Anos mais tarde, em O Capital, obra escrita em meados de 1860, Marx (2018) explica, de maneira bem clara, como o trabalho foi levado à condição de mercadoria na sociedade capitalista. Entretanto, em sua essência, o trabalho, categoria que diferencia o homem de outras espécies animais, é a mediação de outra categoria exclusiva dos homens: a racionalidade. Esta é a consciência, a capacidade de pensar e previamente idealizar o que se pretende com o ato do trabalho. Isto posto, assim expõe Marx: 
Pressupomos o trabalho numa forma em que ele diz respeito unicamente ao homem. Uma aranha executa operações semelhantes às do tecelão, e uma abelha envergonha muitos arquitetos com a estrutura de sua colmeia. Porém, o que desde o início distingue o pior arquiteto da melhor abelha é o fato de que o primeiro tem a colmeia em sua mente antes de construí-la com a cera. No final do processo de trabalho, chega-se a um resultado que já estava presente na representação do trabalhador no início do processo, portanto, um resultado que já existia idealmente. Isso não significa que ele se limite a uma alteração da forma do elemento natural; ele realiza, nesse último, ao mesmo tempo, seu objetivo, que ele sabe que determina, como lei, o tipo e o modo de sua atividade e ao qual ele tem de subordinar sua vontade. (MARX, 2018, p. 255-256).

O agir humano, como elucidado no excerto acima, é constituído por finalidades, ou melhor, é organizado, intencionado pela categoria denominada teleologia. Teleologia são os fins, os objetivos. É a capacidade de raciocinar e previamente idealizar o que se pretende com o ato do trabalho. Em outro texto que escreveu para complementar sua análise, Lukács (1968), após Marx, afirma que "com justa razão se pode designar o homem que trabalha, ou seja, o animal tornado Homem através do trabalho, como um ser que dá respostas." (LUKÁCS, 1968, p. 5 , grifo nosso).

Portanto, o planejamento que antecede e dirige a ação, o trabalho, é a "prévia-ideação" - uma capacidade possível somente nos humanos que precisam responder às suas necessidades porque não têm garantida a sua sobrevivência, tendo que, incessantemente reproduzi-la. Revelando seus fundamentos filosóficos no materialismo histórico-dialético, o estudioso explica que para compreender a complicadíssima interação que constitui o homem - ser social - inicialmente é preciso entender que "devemos ter presente antes de tudo que, sempre que tenha a ver com autênticas transformações do ser, o contexto total do complexo em questão é primário em relação a seus elementos." (LUKÁCS, 2013, p. 64). Assim, a situação concreta e real, a experiência no ambiente material é que tem preponderância sobre o pensamento (a prévia-ideação) sobre a fala, sobre o conceito etc., elementos que surgem como síntese do processo de trabalho, isto é, a socialização e suas instituições são, portanto, conveniências posteriores, secundárias.

No que compete à ação transformadora do trabalho e para se chegar ao seu objetivo de execução, explica o filósofo que é imperativo explorar e identificar o cabedal de recursos e as possibilidades para o transcurso do exercício previamente idealizado. $O$ conhecimento dos meios para se atingir os fins desejados, que é essencial para a consecução, obtém-se com a vivência prática. Lukács (2013) apresenta sua argumentação, referindo-se que a gênese do trabalho é a necessidade: 
O pôr do fim nasce de uma necessidade humano-social; mas, para que ela se torne um autêntico pôr de um fim, é necessário que a investigação dos meios, isto é, o conhecimento da natureza, tenha chegado a certo estágio adequado; quando tal estágio ainda não foi alcançado, o pôr do fim permanece um mero projeto utópico [...]. Uma vez que a investigação da natureza, indispensável ao trabalho, está, antes de tudo, concentrada na preparação dos meios, são esses o principal veículo de garantia social da fixação dos resultados dos processos de trabalho, da continuidade na experiência de trabalho e especialmente de seu desenvolvimento ulterior. (LUKÁCS, 2013, p. 44).

É importante reconhecer, como muito bem fez esse estudioso, que a categoria "Teleologia" é inseparável de outra categoria, a "Causalidade". Isso quer dizer que todo o trabalho no percurso de se chegar a um fim desejado se depara com as influências da causa sobre o efeito e vice-versa. A causalidade é que apresenta os elementos que serão usados como meio para os fins. Esse aspecto é imprescindível para o "pôr do fim" porque nada existe fora de relações causais, ou seja, sem relação de causa e efeito.

Exemplificando sobre a causalidade, o autor usa a lição de uma faca do Paleolítico a qual, feita de pedra, "ela só pode adquirir tal função de ferramenta quando suas propriedades objetivamente presentes, existentes em si, forem adequadas para entrar numa combinação tal que torne isso possível." (LUKÁCS, 2013, p. 42). A causalidade é relevante e conveniente, pois influi diretamente sobre o modo de operar. Entretanto, explica Lukács (2013) que o fim teleológico é que deve ter primazia sobre a causalidade nas ações de reprodução do ser social. O homem como gênero, o ser social, desenvolve-se em condições não estáveis, objetivando o domínio da barreira natural, dando respostas às suas carências enquanto um ser que não tem garantida a sua existência.

Assim, no caso do trabalho meticuloso, intencional, que se objetiva na práxis criativa consciente, a investigação dos meios está a serviço da escolha da melhor alternativa à disposição para se atingir os objetivos pensados de antemão. Decidir sobre as alternativas para se chegar ao fim proposto é um ato perspicaz: requer capacidade de raciocínio, de avaliação e, mesmo em muitas ocasiões em que o tempo reduzido impõe limites para uma rápida decisão, deve-se focar no propósito final da ação do trabalho. A ação teleológica pode alterar a causalidade dada, objetivando-se na produção do novo. A interação entre a teleologia e a causalidade cria um produto previamente idealizado para responder a uma necessidade humana. Nesse sentido, o filósofo afirma que: 
Quando o trabalho é realizado num sentido mais estrito, a alternativa revela ainda mais claramente a sua verdadeira essência: não se trata apenas de um único ato de decisão, mas de um processo, uma ininterrupta cadeia temporal de alternativas sempre novas. Não se pode deixar de perceber, quando se reflete, ainda que rapidamente, sobre qualquer processo de trabalho [...] que nunca se trata simplesmente da execução mecânica de um fim posto. (LUKÁCS, 2013, p. 54).

Em sua análise, Lukács (2013) evidencia dois tipos de necessidades, as quais o ser social precisa dar respostas. Essas duas teleologias são:

a) as primárias: relacionadas à interação homem-natureza, mediada pelo trabalho, visando suprir suas necessidades biológicas básicas para manter-se vivo. Essa relação supre as carências biológicas (fome, sede, frio etc.) e, desse processo primário, a síntese dialética é a cultura, formando um complexo de outras necessidades;

b) as teleologias secundárias: visam suprir as necessidades surgidas a partir da complexidade da vida em sociedade (da cultura) que carece de organização para a sua reprodução, para a manutenção ou superação de uma ordem habitual estabelecida.

Nos complexos que se constituem as interações do ser social, manifestamse novas carências que pedem respostas. Para explicar tal desenvolvimento, Lukács (2013) explana que:

[...] a estrutura originária do trabalho está submetida a mudanças essenciais, enquanto o pôr teleológico não está mais dirigido exclusivamente à transformação dos objetos naturais, à aplicação de processos naturais, mas quer induzir outros homens a realizar por si mesmos determinados pores desse gênero. Tal mudança se torna qualitativamente mais decisiva quando o desenvolvimento conduz a que, para o homem, o próprio modo de comportamento e a própria interioridade passam a ser o objeto do pôr teleológico. O surgimento progressivo, desigual e contraditório desses pores teleológicos é um resultado do desenvolvimento social. (LUKÁCS, 2013, p. 110).

As mudanças essenciais que o autor menciona em sua análise ocorrem porque as intenções do trabalho, com a progressão da consciência, tornamse cada vez mais sociais. Para o desenvolvimento social, as relações precisam ser reproduzidas e, dessa forma, a sociedade vai tornando-se mais complexa. Exemplos dessas teleologias secundárias são: a língua, o conceito, a educação, o Direito, a religião, a política, o Exército. Instituídas a posteriori, são todas instituições e atributos que afloram como necessidade e consequência da divisão social do trabalho.

Sobre essa questão das complexidades do ser social, Lukács (2013) assim se referiu:

A partir dessas interações se desdobra o processo de reprodução do respectivo 
complexo total, e isso de tal modo que os complexos parciais, por serem - ainda que apenas relativamente - autônomos, também se reproduzem, mas em todos esses processos a reprodução da respectiva totalidade compõe o momento predominante nesse sistema múltiplo de interações. (LUKÁCS, 2013, p. 120).

A totalidade social foi dialeticamente formada ao longo do processo histórico de cisão, partindo-se em complexos menores que influenciam e são impelidos pelo movimento do todo. A origem desse desenvolvimento de novas complexidades está na exploração do homem pelo homem. Nesse ponto, assim argumenta Lukács que, "com efeito, o desenvolvimento da divisão do trabalho gera, a partir de sua dinâmica espontânea de desenvolvimento, categorias de cunho social cada vez mais acentuado.” (LUKÁCS, 2013, p. 122). Dessa maneira, o ser social constitui e é constituído em sua totalidade histórica por uma cadeia que o autor denomina de "complexos de complexos" (ou teleologias secundárias) necessária à reprodução, manutenção ou superação da conjuntura concreta.

O interessante é que essas interações reiteradas para a reprodução possibilitam, ou não, o desabrochar da consciência do homem e a consequente passagem à superação. A consciência, como explica Lukács (2013), vive numa situação "paradoxal através da qual - tendo se originado no trabalho, para o trabalho e mediante o trabalho - a consciência do homem intervém em sua atividade de autorreprodução.” (LUKÁCS, 2013, p. 65). É paradoxal, porque há um problema que vem se pôr à consciência - ela pode ser a falsa consciência (alienação), limitada à aceitação e submissão ou há a possibilidade de ascender, ser fecunda e criadora, isto é, à consciência, se apresentam duas possibilidades: a servidão ou a liberdade.

Para o filósofo em questão, a tomada de decisões (ter liberdade) nas posições teleológicas secundárias, nos complexos do ser social, tem sua origem naquilo que é central e fundante da vida do homem - o trabalho - e consiste num ato de consciência que se apoia em processos valorativos para satisfazer necessidades impostas pelo complexo no qual os indivíduos se relacionam. Lukács (2013) é um convicto, tanto quanto Marx (1888) ao afirmar que, ao conhecer a realidade, após encontrar sua verdade, ontologicamente é necessário intervir, ter a liberdade de tomar decisões, realizar uma ação transformadora. Desse modo, o autor argumenta que:

Por isso, o homem que age de modo prático na sociedade encontra diante de si uma segunda natureza, em relação à qual, se quiser manejá-la com sucesso, deve comportar-se da mesma forma que com relação à primeira natureza, ou seja, deve procurar transformar o curso das coisas, que é independente de sua consciência, num fato posto por ele, deve, depois de ter-lhe conhecido a essência, imprimir-lhe a marca da sua vontade. (LUKÁCS, 2013, p. 110). 
A racionalidade operante e reflexiva tem um papel fundamental como atributo exclusivo do ser social. É no cotidiano, nos conflitos e tensões, no interesse entre o indivíduo (o particular) e a sociedade (o gênero) que se constroem os valores que são mutáveis no tempo, mas responsáveis pela tomada de decisões (liberdade) e pela elevação da consciência para a emancipação. A mediação dessas tensões se dá pela ética, buscando superar a dicotomia entre interesses individuais e do gênero. Ciente das contradições desses interesses, o agir com ética está em reconhecer e sujeitar a disposição do pensar de forma particular ao pensamento e ações para com a coletividade ou para com o gênero no tocante à totalidade social. (LUKÁCS, 2013; VÁZQUEZ, 2017).

\section{TRABALHO E EDUCAÇÃO: A FUSÃO E ESSÊNCIA DO HOMEM}

O exposto até aqui teve a intenção de apresentar a centralidade que o trabalho manifesta na constituição do ser social na análise lukácsiana. No entando, o esforço teórico agora é fazer reconhecer a relação trabalho e educação, categorias analíticas elementares para a ontologia da educação, que fundamenta a Pedagogia Histórico-Crítica (PHC). Desse modo, nosso levantamento referente a György Lukács, dialoga também com os escritos de Dermeval Saviani, expoente da Pedagogia historico crítica.

Para tanto, destaca-se nos escritos desses dois autores de referência, o entendimento de que trabalho e educação possuem vínculos ontológicos, pois são atividades especificamente humanas. (LUKÁCS, 2013; SAVIANI, 2007). Diante desse fato, reitera-se que o ser social é síntese do trabalho, isto porque o homem não tem garantida a sua existência. Como argumentado anteriormente, o ser humano deve criar as condições materiais para se manter vivo, num processo histórico que se desdobrou em outras necessidades e teleologias, dentre elas, a educação.

Em uma das poucas passagens em que se referiu especificamente à necessidade da educação em sua obra Ontologia do Ser Social, Lukács (2013) pondera que os animais adultos auxiliam seus filhotes para que se apropriem de comportamentos e destrezas necessárias para a sua vida toda. Entretanto, argumenta Lukács (2013) que “o essencial da educação dos homens, pelo contrário, consiste em capacitá-los a reagir adequadamente aos acontecimentos e às situações novas e imprevisíveis que vierem a ocorrer depois em sua vida." (LUKÁCS, 2013, p. 130). Esse complexo necessário, chamado educação se manifesta no ser social de duas maneiras: de um modo amplo, aprender a viver em sociedade, e de uma maneira estrita, capacitando para o exercício específico de um papel social. 
Saviani (2007), apresentando essa questão da Educação no sentido mais amplo, exemplifica o encadeamento produção/formação do ser social na seguinte citação:

\begin{abstract}
Se a existência humana não é garantida pela natureza, não é uma dádiva natural, mas tem de ser produzida pelos próprios homens, sendo, pois, um produto do trabalho, isso significa que o homem não nasce homem. Ele forma-se homem. Ele não nasce sabendo produzir-se como homem. Ele necessita aprender a ser homem, precisa aprender a produzir sua própria existência. Portanto, a produção do homem é, ao mesmo tempo, a formação do homem, isto é, um processo educativo. A origem da educação coincide, então, com a origem do homem mesmo. (SAVIANI, 2007, p. 154).
\end{abstract}

Dessa forma, a educação nunca será concluída, nem no sentido amplo e nem no sentido estrito. Lukács (2013) exemplifica esse segundo sentido quando argumenta que a vida do homem, "dependendo das circunstâncias, pode terminar numa sociedade de tipo bem diferente e que lhe coloca exigências totalmente distintas daquelas, para as quais a sua educação - sentido estrito - o preparou." (LUKÁCS, 2013, p. 130). O ser social se constitui complexo e mutável, logo a capacitação, a educação do homem precisa se manter initerruptamente porque a sociedade dialeticamente está sempre em movimento. Como a origem do homem enquanto ser social está no trabalho, esse impõe aos indivíduos uma urgente necessidade: a continuidade da reprodução do ser social. Essa reprodução exige a mediação do conhecimento de geração para geração, reiterando as ações e a consequente organização na vida social. Antes de Saviani (2007) argumentar sobre o assunto, Lukács (2013) já analisava a relevante função da educação, quando descrevia que "a problemática da educação remete ao problema sobre o qual está fundada: sua essência consiste em influenciar os homens no sentido de reagirem a novas alternativas de vida do modo socialmente intencionado." (LUKÁCS, 2013, p. 131).

Portanto, pode-se perceber os vínculos ontológicos que fundem Trabalho e Educação em uma relação de causa e efeito. São atividades cruciais e especificamente humanas porque só os homens trabalham intencionalmente e se educam. Tendo embasamento em Lukács para explicar historicamente o desenvolvimento do seu campo de estudo, Saviani (2007) argumenta sobre esse intrínseco elo, quando na gênese do ser social:

A relação entre trabalho e educação é uma relação de identidade. Os homens aprendiam a produzir sua existência no próprio ato de produzi-la. Eles aprendiam a trabalhar trabalhando. Lidando com a natureza, relacionando-se uns com os outros, os homens educavam- se e educavam as novas gerações. (SAVIANI, 2007, p. 154). 
Todavia, trabalho e educação, mesmo se tratando de ações indissociáveis, por decorrência da história, pelo desenvolvimento de novas situações da complexidade social, se cindiram. O trabalho se dividiu e, em consequência, a também educação se dividiu. Assim, Manacorda (1989) e Saviani (2007) avaliam que, com o desenvolvimento da sociedade de classes, efetivou-se a separação entre trabalho e educação. Ademais, ocorreu o desmembramento e a depuração de processos educativos diferenciados para os coletivos opostos que passam a reproduzir a sociedade. Em sua Ontologia, Lukács (2013) explica que cada tipo de sociedade demanda determinados tipos de capacidades de seus indivíduos e assim surge a educação de modo estrito, formal ou institucionalizada. Uma teleologia secundária que precisa responder a uma demanda:

Toda sociedade reivindica certa quantidade de conhecimentos, habilidades, comportamentos etc. de seus membros; o conteúdo, o método, a duração etc. da educação no sentido mais estrito são as consequências das carências sociais daí surgidas. (LUKÁCS, 2013, p. 131).

Nesse sentido, entendendo a explanação da Ontologia lukácsiana, Saviani (2007) argumenta sobre as origens da institucionalização da educação com o desenvolvimento da sociedade de classes, confinada num tempo e espaço específico intitulado escola, observando que:

Se nas sociedades primitivas, [...] a educação consistia numa ação espontânea, [...] com a divisão dos homens em classes, a educação também resulta dividida; diferencia-se, em consequência, a educação destinada à classe dominante daquela a que tem acesso à classe dominada. E é aí que se localiza a origem da escola. A educação dos membros da classe que dispõe de ócio, de lazer, de tempo livre passa a organizar-se na forma escolar, contrapondo-se à educação da maioria, que continua a coincidir com o processo de trabalho. (SAVIANI, 2007, p. 155).

A propriedade privada gerou divisão dos homens e teve efeitos na própria compreensão ontológica do homem, pois, com o seu advento, tornou possível à classe dos proprietários a vida sem trabalhar, "dispondo do ócio, do lazer e do tempo livre”, como mencionado por Saviani (2007). Também Manacorda (1989) lembra que nas sociedades da Antiguidade, no Egito, por exemplo, há aproximadamente 2.500 anos a.C., se vivia a experiência de uma civilização estratificada em hierarquias, que carecia, cada qual, de certos conhecimentos específicos. Aos dominantes da Antiguidade, assinala o autor, impelia a necessidade de "falar bem". Nesse contexto, exigia-se a presença de certos indivíduos com tal capacidade e dispostos à finalidade de capacitar outros mais a reagirem adequadamente às situações imprevisíveis que iriam surgir, respondendo com as habilidades as quais foram qualificados. Isso mostra, portanto, que há mais de quatro mil anos, já havia 
aquela educação, de modo estrito a que Lukács (2013) se referia. Entretanto, como explica Saviani (2007), a educação para a maioria dos indivíduos ainda continua a ocorrer mediante o trabalho. O desenvolvimento da sociedade de classes dividiu o trabalho em manual e intelectual. Consequentemente, a educação teve que responder a esses dois modos, como esclarece Saviani (2007):

Por sua vez, a divisão que se foi processando ao longo da história entre trabalho manual e trabalho intelectual. Após o surgimento da escola, a relação entre trabalho e educação também assume uma dupla identidade. De um lado, continuamos a ter, no caso do trabalho manual, uma educação que se realizava concomitantemente ao próprio processo de trabalho. De outro lado, passamos a ter a educação de tipo escolar destinada à educação para o trabalho intelectual. (SAVIANI, 2007, p. 157).

Tendo por base a história do Ocidente, pode-se afirmar que, em toda a Antiguidade, no período medieval e também no período da Modernidade, que se inicia no final do século XV até meados do século XVIII, a educação para o trabalho intelectual ficou restrita a uma pequena parcela de indivíduos que compunha a elite. Porém, na Idade Moderna, com o início da sociedade capitalista, mediante as relações do capitalismo mercantil e também sob influência da Reforma Protestante, um novo cenário surge para a educação, que vai se tornando uma necessidade crescente para cada vez mais indivíduos, pessoas comuns, que precisam raciocinar matematicamente ou que ousam aprender a ler para se arriscar a interpretar os textos bíblicos. Contudo, é na Idade Contemporânea, desde as revoluções do século XVIII até os dias de hoje, que se apresentaram grandes mudanças no papel que foi atribuído à escola na formação dos indivíduos.

Ciente de que "toda sociedade reivindica certa quantidade de conhecimentos, habilidades, comportamentos, etc.” (LUKÁCS, 2013), Saviani (2007) explica que as revoluções Francesa, a tomada do poder pela burguesia em 1789 e, nesse mesmo período, a Industrial na Inglaterra, com a introdução da máquina no processo produtivo, como eventos processuais que marcaram a entrada dessa nova sociedade, tornam-se também decisivos para a institucionalização da escola, pois:

[...] a estrutura da sociedade deixa de fundar-se em laços naturais para pautarse por laços propriamente sociais, isto é, produzidos pelos próprios homens. Trata-se da sociedade contratual, cuja base é o direito. Com isso, o domínio de uma cultura intelectual, cujo componente mais elementar é o alfabeto, impõe-se como exigência generalizada a todos os membros da sociedade. E a escola, sendo o instrumento por excelência para viabilizar o acesso a esse tipo de cultura, é erigida na forma principal, dominante e generalizada de educação. (SAVIANI, 2007, p. 158). 
Desse modo, reitera-se que a produção e a reprodução do ser social passam a requerer a existência de um tipo específico de atividade humana voltada à formação dos indivíduos. Sendo assim, a educação em sentido estrito (escola), surge, tendo em sua essência, como afirma Lukács (2013), a finalidade de influenciar os indivíduos, objetivando a reação à vida de modo socialmente intencionado.

Cabe destacar, como apontado por Marx (1996), um aspecto contraditório do trabalho na lógica capitalista em que os meios de produção tornam-se também meios de destruição, pois nesse sistema a essência do trabalho está na exploração do trabalhador, transformado em mercadoria. Assim, nesse modo de produção, as relações entre os homens são reificadas. De forma análoga, concebe-se a função da educação que, instituída para a reprodução, agora manifestada na mesma lógica, não está respaldada para a completa humanização do homem, mas, sim, para a sua coisificação.

Destarte, reconhece-se que, a partir do capitalismo, torna-se uma teleologia do ser social a elevação e expansão do processo educativo. (MARX, 1996). Sobre esse aspecto, Saviani (2007) argumenta que:

Com o impacto da Revolução Industrial, os principais países assumiram a tarefa de organizar sistemas nacionais de ensino, buscando generalizar a escola básica. Portanto, à Revolução Industrial correspondeu uma Revolução Educacional: aquela colocou a máquina no centro do processo produtivo; esta erigiu a escola em forma principal e dominante de educação. (SAVIANI, 2007, p. 159).

A título de exemplo, ao refletir sobre a conjuntura brasileira, é possível denotar que situação semelhante ocorre no país com o advento da industrialização. É somente a partir de 1930 que o Estado concebe um sistema nacional de educação, pois a sociedade do Brasil, em anos anteriores a esse processo, não requeriam a existência massiva de tal instituição.

Por seu pioneirismo e por tratar-se de uma obra que representa um movimento teórico contextual que junto de outros autores foram demoninados por Saviani (2005) como teóricos críticos-reprodutivistas, trazemos para essa discussão a clássica análise crítica, realizada por Althusser (1972) quando esse autor se propôs a argumentar sobre a reprodução dos meios de produção, um tema tratado antes por Marx (1996). Contudo, exposto de maneira bem clara à luz de sua teoria dos "aparelhos ideológicos" que, criados pelo Estado, objetivam os interesses da classe dominante, Althusser foi perspicaz ao incluir entre eles a escola. Segundo o autor, a reprodução da força de trabalho que primeiro ocorre 
dentro do mesmo local de produção do capital é realizada pelo salário. Porém, a reprodução da força de trabalho pode também acontecer fora do local de trabalho, em um papel assegurado pela escola.

\footnotetext{
Ora, o que se aprende na Escola? Vai-se mais ou menos longe nos estudos, mas de qualquer maneira, aprende-se a ler, a escrever, a contar, - portanto algumas técnicas, e ainda muito mais coisas, inclusive elementos (que podem ser rudimentares ou pelo contrário aprofundados) de "cultura científica" ou "literária" diretamente utilizáveis nos diferentes lugares da produção [...]. (ALTHUSSER, 1972, p. 20).
}

Esta escola que está a serviço do capital, institucionalizada no contexto do século XVIII e que chega até os nossos dias, tende a sujeitar a massa à ideologia da classe dominante e qualificá-la para o manejo da prática. (ALTHUSSER, 1970). $\mathrm{Na}$ lógica do capital, reitera-se, a função da escola é "coisificar" os homens, formar as pessoas para o "ter", ou seja, o objetivo é dotar os indivíduos de capacidades para a execução eficiente de um ofício, para que tenham uma ocupação, consigam vender sua força no mercado de trabalho. Ademais, explica Althusser (1972) que a escola impõe esse modo como natural, fazendo com que aceitem essa condição, pois todos “[...] devem estar de uma maneira ou de outra 'penetrados' desta ideologia, para desempenharem 'conscienciosamente' a sua tarefa - quer de explorados (os proletários), quer de exploradores (os capitalistas) [...]." (ALTHUSSER, 1972, p. 22). A reificação do homem à condição de mercadoria, dessa maneira, é intencionalmente objetivada numa escola que aliena e passa a ser aceita livremente pela massa que a frequenta e nela se entorpece.

Entretanto, negando parte dessa tese de que a escola serve somente à reprodução, mas, incorporando suas verdades e propondo superações, a educação, ressignificada dentro de uma concepção ontológica, revolucionária (SAVIANI, 2012), não aceita essa tarefa de formar parcialmente os indivíduos para a execução de tarefas. Como uma tendência progressista da educação, a Pedagogia HistóricoCrítica surge argumentando que é possível a emancipação do sujeito se essa for a intencionalidade do docente consciente da ontologia do trabalho educativo. Conhecendo e desvendando as contradições da realidade, compreendendo essa realidade em seu permanente movimento de mudanças, a Educação pode estar a serviço da transformação do ser social. De acordo com Saviani (2012), mediante uma perspectiva historicizadora, é possível aos sujeitos que fazem a educação reconhecer os condicionantes histórico-sociais que limitam suas ações e, assim, entender que a educação e a sociedade se relacionam dialeticamente, existindo também possibilidades, não ficando completamente impotentes. Para esse intelectual, a Educação: 
[...] ainda que elemento determinado, não deixa de influenciar o elemento determinante. Ainda que secundário, nem por isso deixa de ser instrumento importante e por vezes decisivo no processo de transformação da sociedade. (SAVIANI, 2012, p. 66).

Portanto, apresentando as contradições presentes na sociedade, revelando o que está oculto, a educação, numa perspectiva crítico-dialética, tem a função de formar para o ser, isto é, educar sujeitos para que sejam portadores de valores humanos e que esses valores se sobreponham aos apelos do capital. Nesse sentido, é possível ir além e propor uma escola que, num processo intencional de promoção do homem à sua totalidade, não naturalize as estratificações, estereótipos, os conceitos da ideologia dominante, mas que os questione, que leve o alunos ao estranhamento e que, ao final do processo, possibilite a emancipação.

Esse processo de promoção do indivíduo à humanização, em sentido amplo, na vida, e em sentido estrito, na escola, não tem fronteira, são indissociáveis e tem papéis equivalentes, pois a produção da existência humana, argumenta Saviani (2005), se dará pelo “trabalho material', mas também mediante o trabalho "não material" (a produção e mediação do saber existente sobre a natureza e sobre a cultura), categoria na qual se insere a Escola, instituição em que ocorrerá a socialização do saber sistematizado. (SAVIANI, 2005).

Reconstituindo a categoria central, argumenta-se que, no plano geral, o trabalho é a ação transformadora do homem sobre a natureza. Sendo assim, o trabalho ontológico educação também consiste em transformar a natureza: a natureza de alguém que pouco ou nada sabe sobre o "mundo", um ser humano incompleto que tem uma compreensão sincrética, no plano do imediato, mas que, mediante o trabalho consciente de um professor, pode se ver transformado, porque foi levado a conhecer. Por consequência, são abertas as possibilidades de passar a criar e também transformar. Martins (2009) explica, portanto, que educação é "transformação do ser em direção a um ideal humano superior, de tal forma que os esforços para a transformação do indivíduo se tornem indissociáveis dos esforços para a transformação da sociedade.” (MARTINS, 2009, p. 470).

Enfim, nosso estudo apresenta o entendimento do que seria a ontologia da educação na concepção de Lukács, quando ele define que "a problemática da educação remete ao problema sobre o qual está fundada: sua essência consiste em influenciar os homens no sentido de reagirem a novas alternativas de vida do modo socialmente intencionado.” (LUKÁCS, 2013, p. 131). Demosntrando a compreenção das ideais "lukácsianas" de que a educação é um ato intencional de mediar a cultura no indivíduo para que ele se torne sujeito, interagindo na 
coletividade, Saviani (2005), na formulação de sua teoria, a Pedagogia HistóricoCrítica, conceitua o trabalho educativo dentro da visão ontológica do trabalho docente como o:

[...] o ato de produzir, direta e intencionalmente, em cada indivíduo singular, a humanidade que é produzida histórica e coletivamente pelo conjunto dos homens. Assim, o objeto da educação diz respeito, de um lado, à identificação dos elementos culturais que precisam ser assimilados pelos indivíduos da espécie humana para que eles se tornem humanos e, de outro lado e concomitantemente, à descoberta das formas mais adequadas de atingir esse objetivo. (SAVIANI, 2005, p. 12).

O autor está a argumentar sobre o objetivo da educação institucional que é produzir o a humanidade no homem. $\mathrm{O}$ trabalho docente alcança sua finalidade quando cada aluno, em sua particularidade, se apropriar de atributos culturais, produzidos histórica e coletivamente e, por esse domínio, é que tal trabalho tem um estável e pesado valor social.

\section{CONSIDERAÇÕES FINAIS}

Buscou-se nesse levantamento teórico, discutir duas categorias imprescindíveis e mais relevantes do ser social: trabalho e educação, reconhecendo que as ideais "lukácsianas" dialogam com os escritos de Saviani, intelectual orientador da abordagem dialética da educação intitulada por ele como, Pedagogia Histórico-Crítica. Além das obras marxianas, as raízes dessa abordagem são também as contribuições do teórico György Lukács em sua ontologia do ser social.

O entendimento a que chegamos é que Trabalho e Educação surgem numa relação de causa e efeito, tornando-se categorias essenciais para a constituição da sociedade; ambos, ainda que condicionados pelas relações de classe, possibilitam mediante sua ação, a reprodução dessas relações ou a emancipação e a transformação do ser social.

Portanto, afirma-se que num plano concreto a objetivação de uma educação embasada na lógica dialética que procure desenvolver um trabalho que provoque mudanças estruturais, precisa intencionalmente ou teleologicamente, como argumenta Lukács (2013), trabalhar as contradições e desnaturalizar determinados aspectos que ideologicamente são incutidos como verdades. Estar atento às causalidades que permitem desvendar as controvérsias sociais é uma tarefa, é a nobre tarefa no plano ético-político do fazer docente. A educação 
sendo proposta na abordagem dialético-ontológica, sabe-se condicionada e, por essa razão, o educador consciente deve sempre se questionar sobre o que se está a fazer? o que se quer fazer? a quem se está colocando a serviço?.

E, estando a serviço da formação do ser para a coletividade, para a cidadania, essa escola e esse professor não podem deixar de empenhar esforços para possibilitar aos alunos a se perceberem, em seu processo formativo, como sujeitos, como agentes de possíveis transformações, fazendo-os pensar eticamente sobre as contradições para que se sintam parte de um todo e tenham para com esse responsabilidade. A concepção ontológica do trabalho docente e da escola, presentes na abordagem da Pedagogia Histórico-Crítica serve de fundamento para os educadores, conscientes das limitações e do potencial de seu trabalho, reestabelecerem os vínculos perdidos do conhecimento com o trabalho criativo e transformador do indivíduo e da sociedade.

\section{REFERÊNCIAS}

ALTHUSSER, Louis. Aparelhos ideológicos de Estado. Rio de Janeiro: Paz e Terra, 1972.

DUARTE, Newton. Lukács e Saviani: a ontologia do ser social e a pedagogia histórico-crítica. Pedagogia histórico-crítica e a luta de classes na educação escolar. Campinas. Autores Associados, p. 37-57, 2012.

LESSA, Sergio. Para Compreender a Ontologia de Lukács. 3. ed. Ijuí: Edijuí, 2012.

LUKÁCS, György, Para uma ontologia do ser social, II. Tradução Nélio Schneider, Ivo Tonet, Ronaldo Vielmi Fortes. São Paulo: Boitempo, 2013.

MARTINS, Ligia M. Formação de Professores: desafios contemporâneos e alternativas necessárias. In. MENDONÇA, Sueli Guadalupe de Lima, et al. Marx, Gramsci e Vygotski: aproximações. Araraquara: Junqueira\&Marin; Marilia: Cultura Acadêmica, 2009.

Marx, karl. O Capital: Crítica da Economia Política. São Paulo: Nova Cultural, 1996.Disponível em:<https://edisciplinas.usp.br/mod/resource/view. php?id=138581>. Acesso em: 25 mar. 2018.

. Manuscritos econômico-filosóficos. São Paulo: Boitempo, 2004. 
; ENGELS, Friedrich. A ideologia Alemã. Disponível em: <http:// www.dominiopublico.gov.br/download/texto/cv000003.pdf>. Acesso em: 26 maio 2018.

SAVIANI. Dermeval. Escola e Democracia. 36. ed. Campinas: Autores Associados, 2003.

Pedagogia Histórico-Crítica. 9. ed. Campinas: Autores Associados, 2005.

- Trabalho e Educação: fundamentos ontológicos e históricos. Revista Brasileira de Educação. v. 12, nº 34. p. 152-180. jan/abr., 2007.

A Formação Humana na Perspectiva Histórico-Ontológica. In: SAVIANI, Dermeval; DUARTE, Newton (Org.). Pedagogia histórico-crítica e luta de classes na educação escolar. Campinas: Autores Associados, 2015. p. 13-35.

VÁZQUEZ, Adolfo Sanches. Ética. 37. ed. Rio de Janeiro: Civilização Brasileira, 2017.

ADRIANA REGINA DE JESUS SANTOS é Pós Doutora em Educação pela Universidade Federal Fluminense. Doutora em Educação pela Pontifícia Católica de São Paulo. Docente do Programa de Mestrado e Doutorado em Educação da Universidade Estadual de Londrina. Líder do grupo de Pesquisa pelo CNPq: Currículo, Formação e Trabalho Docente.

E-mail: adrianatecnologia@yahoo.com.br

ORCID: http://orcid.org/0000-0002-9346-5311

JOSÉ ALEXANDRE GONÇALVES é Mestre em Educação pela Universidade Estadual de Londrina. Professor da rede estadual de educação do Estado do Paraná. Participante do grupo de Pesquisa pelo CNPq: Currículo, Formação e Trabalho Docente.

E-mail: alexandregeopg@gmail.com

ORCID: http://orcid.org/0000-0002-3254-0576 